\title{
Minimizing ammonia volatilization from urea in waterlogged condition using chicken litter biochar
}

\begin{abstract}
Application of urea in lowland rice fields leads to ammonia (NH3) volatilization and environmental pollution, and diminishes nitrogen recovery by rice (Oryza sativa L.). Amending urea with biochar could reduce NH3 loss from urea as well as improve chemical properties of acid soils. An incubation study was conducted using a closed-dynamic air flow system to determine NH3 volatilization from urea and chemical properties of an acid soil (Typic Paleudults). The soil was mixed with three rates of chicken litter biochar (20, 40, and $60 \mathrm{~g}$ pot-1) and $1.31 \mathrm{~g}$ urea. Mixing an acid soil with biochar $(60 \mathrm{~g} \mathrm{pot}-1)$ in waterlogged to stimulate conditions in paddy condition significantly reduced NH3 loss and total titratable acidity. Biochar application also increased soil $\mathrm{pH}$, total nitrogen, available nitrate, organic matter, total organic carbon, total carbon, available phosphorus, and exchangeable cations. Thus, chicken litter biochar can be used to reduce urea-N loss and ameliorate chemical properties of acid soils. This aspect is being embarked on in our on-going field experiments.
\end{abstract}

Keyword: Ammonia loss; Available nitrate; Chicken litter biochar; Exchangeable ammonium; Soil chemical properties; Urea 